\title{
Letter to the Editor: Awareness and Understanding of Dementia in Community-Dwelling Adults Without Dementia and Stroke
}

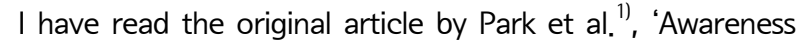
and Understanding of Dementia in Community-Dwelling Adults Without Dementia and Stroke' with great interest. As suggested in the original article, understanding and knowledge of dementia is very important for the general population. Dementia is one of the most distressing and burdensome mental health problems in the aged population ${ }^{2)}$. Although acetylcholinesterase inhibitors (e.g., tacrine, donepezil, rivastigmine, and galantamine) and $\mathrm{N}$-methyl-D-aspartate receptor antagonists (e.g., memantine) have demonstrated efficacy in the temporal symptomatic control of cognitive decline and daily function in dementia patients, their effect is not sufficient to restore premorbid function ${ }^{3)}$. Therefore, prevention and early diagnosis of dementia is very important to decrease the prevalence and progression of dementia.

The Korean government has made an effort to prevent and diagnose dementia early over the last decade. To achieve these aims, knowledge of dementia among the general population is indispensable. In regards to this point, this study has obvious academic value. Based on the academic value of this article, I suggest adding text that addresses some questions related to the description and analysis:

First, how did the investigators diagnose dementia and stroke? Because dementia or stroke can affect the cognitive function of subjects, the diagnostic process is very important to ensure that the subjects are cognitively normal. I think

\author{
Seok Bum Lee \\ Department of Psychiatry, Dankook University Hospital, Dankook \\ University College of Medicine, Cheonan, Korea \\ Corresponding Author: Seok Bum Lee, MD, PhD \\ Department of Psychiatry, Dankook University College of Medicine, \\ 119 Dandae-ro, Dongnam-gu, Cheonan 31116, Korea \\ Tel: +82-41-550-3795, Fax: +82-41-561-3007 \\ E-mail: bumlee@dankook.ac.kr
}

Received: March 2, 2017

Revised: March 3, 2017

Accepted: March 7, 2017 that a detailed evaluation process was presented in the article about The Prevention of Stroke and Dementia (PRESENT) project. However, there was no reference to the PRESENT project. If possible, providing additional references can help readers who are interested in this article.

Second, how was the questionnaire evaluating the knowledge of dementia developed? As cited in reference 6 of the original article, there is already an article about a representative nationwide survey exploring knowledge of dementia. The questionnaire consisted of 14 items $^{4}$. Explaining the process of developing the questionnaire and comparing differences in the questionnaires between the 2 studies will be very informative.

Third, among the 13 questions, only 1 question required 'No' as a correct answer. Sometimes, responders answer all questions with all 'Yes' or all 'No.' In this questionnaire, in cases of all 'Yes,' they will be classified as having 12 correct knowledge items of dementia among the 13 possible. This score is higher than the mean score (9.8) of subjects who are considered to be 'very much aware' individuals. Thus, I think that presenting the proportion of subjects who responded to all questions by answering all 'Yes' or all 'No' will be very informative.

In summary, Park et al. ${ }^{1)}$ conducted a valuable study that examined the degree of interest in dementia, comprehension of dementia, and level of knowledge about dementia with a relatively large sample size. However, as suggested above, adding additional information will improve the quality and value of this article significantly.

Conflicts of Interest Disclosures: The researcher claims no conflicts of interest.

\section{REFERENCES}

1. Park HY, Kim YS, Park HJ, Lee HS, Suk SH. Awareness and understanding of dementia in community-dwelling adults without dementia and stroke. Ann Geriatr Med Res 2016;20:204-8.

2. Jhoo JH, Kim KW, Huh Y, Lee SB, Park JH, Lee JJ, et al. Prevalence of dementia and its subtypes in an elderly urban Korean population: results from the Korean Longitudinal Study 
on Health and Aging (KLoSHA). Dement Geriatr Cogn Disord 2008;26:270-6.

3. Lee SB, Park CS, Jeong JW, Choe JY, Hwang YJ, Park CA, et al. Effects of spaced retrieval training (SRT) on cognitive function in Alzheimer's disease (AD) patients. Arch Gerontol Geriatr 2009; 49:289-93.
4. Lee JY, Park S, Kim KW, Kwon JE, Park JH, Kim MD, et al. Differences in knowledge of dementia among older adults with normal cognition, mild cognitive impairment, and dementia: a representative nationwide sample of Korean elders. Arch Gerontol Geriatr 2016;66:82-8. 